\title{
SELEÇÃO DE HÍBRIDOS DE CUPUAÇUZEIRO QUANTO À CAPACIDADE PRODUTIVA, DESENVOLVIMENTO VEGETATIVO E RESISTÊNCIA À VASSOURA-DE-BRUXA NO MUNICÍPIO DE TERRA ALTA - PA
}

Paulo Henrique Batista Dias ${ }^{1}$, Rafael Moysés Alves ${ }^{2}$, Abel Jamir Ribeiro Bastos ${ }^{3}$, José Raimundo Quadros Fernandes ${ }^{4}$

\footnotetext{
${ }^{1}$ Graduando do curso de Agronomia, Universidade Federal Rural da Amazônia, Bolsista da Embrapa Amazônia Oriental. Email: paulo.dias20@hotmail.com.

${ }^{2}$ Pesquisador da Embrapa Amazônia Oriental, Laboratório de Fitomelhoramento. E-mail: rafael-moyses.alves@embrapa.br. ${ }^{3}$ Graduando do curso de Agronomia, Universidade Federal Rural da Amazônia; Bolsista da Embrapa Amazônia Oriental. Email: abel.bastos.ufra@gmail.com.

${ }^{4}$ Técnico agrícola, Embrapa Amazônia Oriental. E-mail: jose.quadros-fernandes@embrapa.br.
}

Resumo: O cupuaçuzeiro (Theobroma grandiflorum) é uma das fruteiras amazônicas mais importantes, sendo o estado do Pará o principal produtor. Este trabalho teve por objetivo avaliar a capacidade produtiva, o desenvolvimento vegetativo e a resistência à vassoura-de-bruxa em progênies de cupuaçuzeiro, instaladas em plantio de pequeno produtor rural no município de Terra Alta. O delineamento experimental utilizado foi em blocos casualizados, com 25 progênies de cupuaçuzeiro, cinco repetições e três plantas por parcela. Foram analisadas a altura da planta, diâmetro do caule, produção de frutos e o nível de incidência de vassoura de bruxa na safra 2016/2017. A análise de variância individual realizada no trabalho demonstrou que a progênie 76 apresentou bons valores para altura e diâmetro, porém não diferiu das progênies 58,60, 64, 69, 72, 76, 88 e 89 para altura. Já para a variável número médio de frutos a melhor resposta foi obtida pela progênie 69 , sendo diferenciada de todos os demais materiais. Visando o aumento da base genética do cupuaçuzeiro, as progênies 69 e 73 deverão ser incorporadas aos testes de progênies em larga escala no programa de melhoramento do cupuaçuzeiro, desenvolvido pela Embrapa Amazônia Oriental, pois ambas apresentaram boas respostas para todas as variáveis analisadas.

Palavras-chave: fruteira nativa, melhoramento vegetal, progênies, Theobroma grandiflorum

\section{Introdução}

O cupuaçuzeiro (Theobroma grandiflorum Schum.) é uma fruteira perene, que apresenta como principais características o aroma intenso e agradável do fruto, o sabor exótico da polpa, e amêndoas ricas em óleo, que credenciam essa espécie como uma das fruteiras nativas mais promissoras do Norte brasileiro (CALZAVARA et al., 1984). Entretanto, para a realização dos plantios pioneiros os produtores utilizaram sementes sem nenhum critério de seleção. Após alguns anos de cultivo a doença conhecida 
como vassoura-de-bruxa, cujo agente etiológico é o fitopatógeno Moniliophthora perniciosa, (Stahel) Singer, passou a atacar os plantios, inicialmente de maneira endêmica e, posteriormente, na forma de epidemia (ALVES et al., 1998). Com isso o aparecimento de novos isolados do fungo em plantios na região amazônica é bastante provável, visto que, por ser essa região o centro de origem do cupuaçuzeiro, acredita-se que todos os patógenos coevoluíram com o cupuaçuzeiro ao longo do tempo. Assim, materiais de plantação com diferentes fontes de resistência constituiriam um efeito multilinha, que proporcionaria maior capacidade para suportar o ataque da doença (ALVES et al., 1998).

Objetivou-se neste trabalho avaliar a capacidade produtiva, o desenvolvimento das plantas e a resistência à vassoura-de-bruxa, de 25 progênies de irmãos completos de cupuaçuzeiro, instaladas em plantio comercial de produtor rural localizado no município de Terra Alta - PA.

\section{Material e Métodos}

O experimento foi conduzido em Sistema Agroflorestal (SAF) uma área localizada no município de Terra Alta-PA. Essa área apresenta clima do tipo Ami, da classificação de Köppen, caracterizado por apresentar um índice pluviométrico elevado, com total anual de $2.000 \mathrm{~mm}$, aproximadamente, e temperatura média de $26^{\circ} \mathrm{C}$ (BASTOS, 1972).

Os materiais utilizados no experimento foram híbridos tri-compostos (progênies de irmãos completos) oriundos de cruzamentos entre parentais do programa de melhoramento de cupuaçuzeiro da Embrapa Amazônia Oriental, utilizando-se 25 progênies de irmãos completos, em plantio realizado no ano de 2006 e foi utilizado para as avaliações as safras 2016/17.

A área do experimento era composta por um sistema agroflorestal incluindo três culturas, o taperebazeiro (Spondias mombin L.) disposto em um espaçamento de $30 \times 30 \mathrm{~m}$, a bananeira (Musa spp.) em um espaçamento de 5 x $5 \mathrm{~m}$ e o cupuaçuzeiro, seguindo o mesmo espaçamento anterior.

$\mathrm{O}$ experimento foi realizado em delineamento inteiramente casualizados com 25 tratamentos, 5 blocos e sendo alocada 3 plantas por parcela, totalizando 375 unidades experimentais.

As variáveis foram avaliadas após a safra 2016/2017, sendo estas o desenvolvimento vegetativo (altura e diâmetro) e produção de frutos, além da ocorrência de vassoura-de-bruxa em percentual de plantas infectadas. Os resultados foram submetidos à análise de variância e as médias comparadas pelo teste de Scott-Knott ao nível de 5\% de probabilidade com o programa estatístico GENES (CRUZ, 2013).

\section{Resultados e Discussão}

A análise de variância individual realizada e demonstrada na Tabela 1 indicou que os valores referentes à altura da planta mostraram-se favoráveis à progênie 76, apresentando um valor de 3,04 m. Entretanto esse material não se diferenciou estaticamente das progênies 58, 60, 64, 69, 72, 76, 88 e 89 , 
com os valores de 2,$86 ; 2,95 ; 3,0 ; 2,76 ; 2,93 ; 2,81$ e 2,74 , respectivamente.

Para a variável diâmetro do caule identificou-se que a progênie 76 também apresentou a maior média, com um valor de $5,06 \mathrm{~cm}$, contudo, não se diferenciando estatisticamente dos demais materiais, como demonstrado na Tabela 1.

Já a progênie 69 apresentou a maior média de número de frutos na safra, com 15,46 frutos/planta/safra. Diferenciando-se estatisticamente de todas as demais progênies.

Quanto a tolerância à incidência da vassoura-de-bruxa foi possível observar que as progênies 58, $60,61,64,66,69,72,73,76,78,80,82,84,86,87,88,89$ e 93 apresentaram-se livres da doença no período em que foram avaliadas. Vale salientar que todas têm como um dos parentais as cultivares Coari (174), Codajás (186), Manacapuru (215) e Belém (286), materiais esses comprovadamente resistentes e que podem conferir boas taxas de resistência aos seus descendentes através de cruzamentos controlados (ALVES et al., 2009). Em contrapartida a progênie com maior incidência da doença foi a 74, e que apresenta como um dos seus parentais a progênie 1074, característico pela elevada suscetibilidade à vassoura-de-bruxa, segundo Alves et al. (2009).

Tabela 1: Média de altura (m), diâmetro (cm), produção de frutos/planta/safra (safra 2016/2017) e ocorrência de vassoura-de-bruxa no cupuaçuzeiro no município de Terra Alta, Belém, 2017.

\begin{tabular}{ccccccccc}
\hline Progênie & Parentais & Altura $(\mathrm{m})^{*}$ & Diâmetro $(\mathrm{cm})^{*}$ & $\begin{array}{c}\text { Número de } \\
\text { Frutos* }\end{array}$ & $\begin{array}{c}\text { Ocorrência de } \\
\text { Vassoura }(\%)^{* *}\end{array}$ \\
\hline 57 & $215 \times(174 \times 554)$ & 2,58 & $\mathrm{~b}$ & 3,70 & $\mathrm{a}$ & 7,16 & $\mathrm{~d}$ & 6,6 \\
58 & $215 \times(186 \times 1074)$ & 2,86 & $\mathrm{a}$ & 4,56 & $\mathrm{a}$ & 6,00 & $\mathrm{~d}$ & 0,0 \\
60 & $215 \times(554 \times 1074)$ & 2,95 & $\mathrm{a}$ & 4,69 & $\mathrm{a}$ & 8,41 & $\mathrm{c}$ & 0,0 \\
61 & $286 \times(186 \times 1074)$ & 2,60 & $\mathrm{~b}$ & 4,27 & $\mathrm{a}$ & 5,50 & $\mathrm{~d}$ & 0,0 \\
64 & $554 \times(174 \times 186)$ & 3,02 & $\mathrm{a}$ & 4,93 & $\mathrm{a}$ & 5,23 & $\mathrm{~d}$ & 0,0 \\
66 & $554 \times(174 \times 286)$ & 2,67 & $\mathrm{~b}$ & 4,16 & $\mathrm{a}$ & 6,47 & $\mathrm{~d}$ & 0,0 \\
67 & $554 \times(286 \times 215)$ & 2,56 & $\mathrm{~b}$ & 4,24 & $\mathrm{a}$ & 7,46 & $\mathrm{~d}$ & 6,6 \\
69 & $1074 \times(174 \times 186)$ & 2,76 & $\mathrm{a}$ & 4,96 & $\mathrm{a}$ & 15,46 & $\mathrm{a}$ & 0,0 \\
71 & $1074 \times(174 \times 286)$ & 2,62 & $\mathrm{~b}$ & 4,28 & $\mathrm{a}$ & 5,87 & $\mathrm{~d}$ & 6,6 \\
72 & $1074 \times(174 \times 286)$ & 2,93 & $\mathrm{a}$ & 4,77 & $\mathrm{a}$ & 8,05 & $\mathrm{c}$ & 0,0 \\
73 & $1074 \times(174 \times 554)$ & 2,41 & $\mathrm{~b}$ & 4,12 & $\mathrm{a}$ & 12,25 & $\mathrm{~b}$ & 0,0 \\
74 & $1074 \times(174 \times 554)$ & 2,60 & $\mathrm{~b}$ & 4,56 & $\mathrm{a}$ & 10,87 & $\mathrm{c}$ & 13,3 \\
75 & $1074 \times(186 \times 554)$ & 2,55 & $\mathrm{~b}$ & 4,28 & $\mathrm{a}$ & 8,50 & $\mathrm{c}$ & 6,6 \\
76 & $1074 \times(186 \times 215)$ & 3,04 & $\mathrm{a}$ & 5,06 & $\mathrm{a}$ & 6,47 & $\mathrm{~d}$ & 0,0 \\
77 & $1074 \times(286 \times 215)$ & 2,29 & $\mathrm{~b}$ & 3,92 & $\mathrm{a}$ & 4,90 & $\mathrm{e}$ & 6,7 \\
78 & $186 \times(174 \times 286)$ & 2,30 & $\mathrm{~b}$ & 3,84 & $\mathrm{a}$ & 3,24 & $\mathrm{e}$ & 0,0 \\
80 & $186 \times(174 \times 554)$ & 2,26 & $\mathrm{~b}$ & 4,02 & $\mathrm{a}$ & 9,14 & $\mathrm{c}$ & 0,0 \\
81 & $186 \times(286 \times 215)$ & 2,25 & $\mathrm{~b}$ & 3,94 & $\mathrm{a}$ & 5,63 & $\mathrm{~d}$ & 6,7 \\
82 & $186 \times(286 \times 215)$ & 2,61 & $\mathrm{~b}$ & 4,44 & $\mathrm{a}$ & 5,19 & $\mathrm{~d}$ & 0,0 \\
84 & $174 \times(286 \times 215)$ & 2,47 & $\mathrm{~b}$ & 4,38 & $\mathrm{a}$ & 4,67 & $\mathrm{e}$ & 0,0
\end{tabular}




\begin{tabular}{ccccccccc}
86 & $174 \times(186 \times 1074)$ & 2,52 & $\mathrm{~b}$ & 4,05 & $\mathrm{a}$ & 4,23 & $\mathrm{e}$ & 0,0 \\
87 & $174 \times(186 \times 1074)$ & 2,56 & $\mathrm{~b}$ & 4,55 & $\mathrm{a}$ & 9,11 & $\mathrm{c}$ & 0,0 \\
88 & $174 \times(554 \times 1074)$ & 2,81 & $\mathrm{a}$ & 4,74 & $\mathrm{a}$ & 5,72 & $\mathrm{~d}$ & 0,0 \\
89 & $174 \times(554 \times 1074)$ & 2,74 & $\mathrm{a}$ & 4,41 & $\mathrm{a}$ & 2,91 & $\mathrm{e}$ & 0,0 \\
93 & SEKO X $(174 \times$ & 2,37 & $\mathrm{~b}$ & 3,96 & $\mathrm{a}$ & 5,29 & $\mathrm{~d}$ & 0,0 \\
\hline & $186)$ & & & & & \\
& Média & 2,61 & & 4,35 & & 6,95 & & \\
& C.V. $(\%)$ & 22,89 & 13,23 & & 15,03 & & \\
\hline
\end{tabular}

* Médias seguidas de mesma letra minúscula na vertical não diferem entre si, ao nível de significância de 5\%, pelo teste de Scott-Knott.

** Percentagem de infestação da vassoura de bruxa na safra 2016/2017.

Fonte: Embrapa Amazônia Oriental.

\section{Conclusões}

De acordo com as análises demonstradas no trabalho, as progênies 69 e 76 apresentaram resultados satisfatórios quanto ao desenvolvimento vegetativo e produção de frutos, além de boa resistência à ação da vassoura-de-bruxa. Esses materiais apresentam características que conferem atributos interessantes para dar continuidade ao programa de melhoramento genético e para o aumento da base genética da espécie.

\section{Referências Bibliográficas}

ALVES, R. M.; RESENDE, M. D. V.; BANDEIRA, B. S.; PINHEIRO, T. M.; FARIAS, D. C. R. Evolução da vassoura-de-bruxa e avaliação da resistência em progênies de cupuaçuzeiro. Revista Brasileira de Fruticultura, v. 3, n. 4, p. 1022-1032, 2009.

ALVES, R. M.; STEIN, R. L. B.; ARAÚJO, D. G.; PIMENTEL, L. Avaliação de clones de cupuaçuzeiro quanto à resistência a vassoura-de-bruxa. Revista Brasileira de Fruticultura, v. 20, n. 3, p. 297-306, 1998.

BASTOS, T. X. O estado atual do conhecimento das condições climáticas da Amazônia brasileira. In: ZONEAMENTO Agrícola da Amazônia. Belém, PA: IPEAN, 1972. p. 68-122. (IPEAN. Boletim técnico, $54)$.

CAlZAVARA, B. B. G.; MUller, C. H.; KAHWAGE, O. N. C. Fruticultura tropical: o cupuaçuzeiro: cultivo, beneficiamento e utilização do fruto. Belém, PA: EMBRAPA-CPATU, 1984. 101 p. (EMBRAPA-CPATU. Documentos, 32).

CRUZ, C. D. GENES - a software package for analysis in experimental statistics and quantitative genetics. Acta Scientiarum, v. 35, n. 3, p. 271-276, 2013. 